Винокурова М. А., Коноплёва Н. А.

M. A. Vinokurova, N. A. Konopleva

ПРОДВИЖЕНИЕ ПОВСЕДНЕВНОЙ КУЛЬТУРЫ ПИТАНИЯ ЯКУТСКОГО ЭТНОСА В КОНТЕКСТЕ РАЗВИТИЯ ГАСТРОНОМИЧЕСКОГО ТУРИЗМА РЕГИОНА

\title{
PROMOTION OF THE EVERYDAY CULTURE OF YAKUT ETHNOS NUTRITION IN THE CONTEXT OF GASTRONOMIC TOURISM DEVELOPMENT IN THE REGION
}

Винокурова Марфа Александрова - старший преподаватель кафедры социально-культурного сервиса и туризма Северо-Восточного федерального университета имени М. К. Аммосова (Россия, Якутск); 677000, Республика Саха (Якутия), г. Якутск, ул. Белинского, 58; тел: +7 (4112) 49-67-55. E-mail: vinokurova.21@mail.ru.

Ms Marfa A. Vinokurova - sr. instructor, socio-cultural service and tourism department, Northeastern Federal University named after M. K. Ammosov (Russia, Yakutsk); 677000, Republic of Sakha (Yakutia), Yakutsk, 58 Belinsky str.; tel.: +7 (4112) 49-67-55. E-mail: vinokurova.21@mail.ru.

Коноплёва Нина Алексеевна - доктор культурологии, профессор Владивостокского государственного университета экономики и сервиса (Россия, Владивосток); 690014, Приморский край, г. Владивосток, ул. Гоголя, 41; тел: +7 (914) 656-70-42. E-mail: nika.Konopleva@gmail.com.

Ms Nina A. Konopleva - Doctor of Culture studies, Professor, Vladivostok State University of Economics and Service (Russia, Vladivostok); 690014, Primorsky territory, Vladivostok, 41 Gogol str.; tel.: +7 (914) 656-70-42. E-mail: nika.Konopleva@gmail.com.

Аннотация. В статье рассматриваются теории повседневности, разработанные зарубежными и отечественными историками и философами культуры. Особое внимание уделяется повседневной культуре питания народа республики Саха (Якутия). Пища - неотъемлемый элемент человеческой жизнедеятельности, в связи с чем исторически формировались принципы культуры питания, включающие в себя знание основ правильного питания, свойств продуктов, их воздействия на организм; умение их выбирать, готовить, подавать на стол и прочее. В связи с этим термин «культура питания» соотносят с накопленным народом как носителем культуры опытом удовлетворения потребности в пище. В современной науке повседневную культуру питания соотносят с дефиницией «гастрономическая культура», хотя до настоящего времени нет однозначного осмысления этого многоаспектного культурного феномена, являющегося специфическим атрибутом каждого народа.

Summary. The article discusses the theory of everyday life, developed by foreign and domestic historians and philosophers of culture. Particular attention is paid to the daily food culture of the people of the Republic of Sakha (Yakutia). Food serves as an integral element of human activity, and therefore historically formed the principles of food culture, including knowledge of the basics of proper nutrition, the properties of products, and their effects on the body, the ability to choose, cook, and serve, and so on. In this connection, the term «food culture» correlates with the accumulated people - the bearer of the culture - the experience of satisfying the need for food. In modern science, everyday food culture is correlated with the definition of «gastronomic culture», although, there is no unequivocal understanding of this multidimensional cultural phenomenon, which is a specific attribute of every nation.

Ключевые слова: повседневность, культура питания, гастрономическая культура, гастрономический туризм, народ саха, якутская национальная кухня.

Key words: Daily routine, food culture, gastronomic culture, gastronomic tourism, Sakha people, Yakut national cuisine.

УДК 008: 392.8 
Винокурова М. А., Коноплёва Н. А.

ПРОДВИЖЕНИЕ ПОВСЕДНЕВНОЙ КУЛЬТУРЫ ПИТАНИЯ ЯКУТСКОГО ЭТНОСА В КОНТЕКСТЕ РАЗВИТИЯ ГАСТРОНОМИЧЕСКОГО ТУРИЗМА РЕГИОНА

Актуальность представленной статьи обусловлена медленным развитием в российской науке исследований истории и культуры повседневности отдельных этносов, хотя это считается важным научным аспектом. Продемонстрировать особенности конкретной цивилизации во всём её разнообразии позволяет обращение не только к достижениям её культуры, историко-культурному наследию, но и к повседневности, действительности ежедневного существования людей. Повседневная культура рассматривается нами как комплекс идей, правил, действий и явлений культуры, сопряжённых с обыденной жизнью людей и позиционирующих сущностные черты культуры в целом. Обыденность играет важную роль в функционировании культуры сообщества и отдельного региона, а культура обыденности прямо воздействует на развитие региональной идентичности и самосознания жителей.

Интерес к повседневности актуализировался у историков во второй половине XIX века. Существуют научные подходы, культурно-философские и социологические трактовки понятия «повседневность». Так, в западной науке изучение повседневности происходит в основном в рамках философии и социальной феноменологии. Методологические аспекты повседневности рассматриваются в феноменологии Э. Гуссерля, социологии М. Вебера и А. Шюца, этнометодологии Г. Гарфинкеля. Особый интерес представляют труды французского структуралиста Р. Барта $[11,159]$, посвящённые мифологии повседневной жизни, и базовое её исследование, проведённое Ф. Броделем $[6,56]$. В свою очередь, в центре внимания Э. Гуссерля находится вопрос интерсубъектности, связанный с формированием единых принципов восприятия и формирования понятий об окружающем мире, причём значимым для исследования культуры повседневности является учение Э. Гуссерля о «жизненном мире» как структуре практической жизнедеятельности человека, представления о которой им не отрефлексированы. Если направить внимание учёных на раскрытие данной бессознательной информации, то это может способствовать познанию и раскрытию сущности непосредственного повседневного бытия человека в аспектах его культурноисторической жизнедеятельности. Согласно суждению А. Шюца главной проблемой феноменологической социологии считается исследование и описание обыденной жизни, то есть жизненного мира и связанных с ним состояний сознания.

В отличие от А. Шюца, П. Бергер и Т. Лукман $[4,11]$ заявляли о потребности формирования самим человеком устойчивой окружающей среды с целью институционализации ролей и моделей действий в повседневном мире. Концепция конструирования социальной реальности T. Лукмана и П. Бергера базируется на иерархии обыденных действий, взаимоотношений и познания. Данная концепция основывается на методологической теории представления и интерпретации повседневности, дополненной А. Шюцем.

В отечественных гуманитарных науках исследование повседневности не имеет столь длительной традиции, как на Западе, тем не менее рассматривается в работах М. А. Барга, М. М. Баткина, М. М. Бахтина, А. В. Беловой, М. М Брагиной, А. Я. Гуревича, 3. Е. Дорофеевой, Л. Г. Ионина, Л. П. Карсавина, Г. С. Кнабе, Н. Л. Пушкаревой, Ю. А. Полякова, Н. Е. Соколовой-Семпер, С. С. Соковикова и др., причём 3. Е. Дорофеева, Ю. А. Поляков обосновывают необходимость в этих исследованиях междисциплинарного подхода, использования как общественных наук, так и психологических, литературоведческих [7, 290; 2]. В связи с этим фактором мы полагаем, что наиболее значимым в подобных исследованиях этнической культуры будет культурноантропологический подход. При этом для любого исследователя важно обратить внимание на описание источников информации и культурных артефактов, сделанное 3. Е. Дорофеевой, изучение которых позволит учёным получить подробные достоверные сведения о культуре повседневности [2].

Особенность повседневности как культурно-исторического феномена состоит в её локальных проявлениях на территории определённых регионов и стран.

Можно отметить, что повседневность предстаёт как обобщающее понятие, включающее в себя не только конкретные условия существования и устойчивые стереотипные примеры действия и решения человеком жизненных проблем, но и индивидуальные переживания, взгляды, оценки и методы мировосприятия, свойственные повседневной жизни. 


\section{Учёные записки}

Комсомольского-на-Амуре государственного технического университета

Вместе с тем длительное время никакая иная область человеческого существования, кроме повседневной, обыденной жизни, не рассматривалась как область, далёкая от культуры. Повседневность лежала за пределами исследований культуры.

Основатель культурологии Л. Уайт выдвинул идею, будто культура - это прежде всего значимая символическая действительность. Своеобразной особенностью данной действительности считается восприятие и оценка объектов и явлений не с точки зрения их физиологических характеристик и практических функций, а с позиций социальной важности, которая условна и при этом разделяется абсолютно всеми резидентами общества. Там, где появляются значения и смыслы, не предопределённые объективными практическими чертами, мы можем заявлять о культуре.

Понятие «обыденность» можно охарактеризовать как особенную область существования людей в мире. Она позиционирует жизненную сферу человека, область непосредственного потребления, удовлетворения вещественных и духовных потребностей, связанных с нравами, ритуалами, формами действий, привычками. В этом случае обыденность включает достаточно разнородный перечень критериев исследования: привычную трудовую деятельность, этикетные формы поведения, техники решения профессиональных и бытовых трудностей, сегмент организации развлечений, стереотипы и предрассудки, которых придерживается человек в своей деятельности.

Кроме того, повседневную жизнь невозможно рассматривать обособленно от системы ценностей той или иной социальной общности. Нравственные приоритеты каждого человека не только формируются в его повседневной среде - они, как и весь социум, оказывают влияние на образ жизни личности, на её установки и жизненные ориентиры. Таким образом, повседневность - это и образ жизни, и множественность направлений деятельности, и принципы взаимодействия с внешним окружением, и особенности внутреннего мира индивида, его ценностные ориентиры и эмоциональные переживания.

Культура повседневности - одна из распространённых сфер нынешнего гуманитарного познания. Рост заинтересованности в её исследовании указывает на желание учёных-культурологов овладеть новейшими научными областями и доминирование в современной науке микроисторического подхода, интереса непосредственно к обыденности отдельного индивида и народа в целом. При этом заинтересованность предполагает как изучение обыденности в свойстве сравнительнонезависимого «мира опыта» (А. Шюц), так и анализ её в связи с иными сферами культуры. Исследование повседневности позволяет сформировать многомерную картину культуры в её двойственности и единстве.

Повседневность - особенный способ существования человека и общества, первичный для человека. Культурологический ракурс изучения обыденности сопряжён с культурой повседневности, которая предполагает цеенностно-символический подход к повседневности. Из числа многообразных трактовок культуры сущности понятия «повседневность» соответствует понимание культуры как особенности жизнедеятельности этноса. В повседневности акиентируется как материальный уровень предметов, так и духовный уровень норм, иенностей, верований, убеждений, мыслей и правил.

Одним из важных компонентов повседневной культуры любой страны считается гастрономия. Гастрономическую культуру можно определить как цивилизованно специфичную концепцию общепризнанных норм, принципов и стандартов, воплощающихся в способах приготовления еды, наборе принятых в конкретной культуре продуктов и их сочетаниях, практике культуры питания. Еда становится символом многих общественных и культурных явлений и основой базовых метафор, описывающих в том числе интеллектуальную деятельность человека.

Культура питания - это характеристика реализации и воплощения в питании ценностных смыслов культуры путём оформления, обработки, одухотворения такой существенной для людей сферы их жизнедеятельности.

В свойственных различным народам комплектах пищевых продуктов, методах их обработки, типах блюд, традициях их предпочтения, организации и ритуале приёмов еды и других нюансах культуры повседневности, прямо или косвенно связанных с едой, отражается этническая и культурно историческая особенности народа, природно-географические особенности проживания. 
Винокурова М. А., Коноплёва Н. А.

ПРОДВИЖЕНИЕ ПОВСЕДНЕВНОЙ КУЛЬТУРЫ ПИТАНИЯ ЯКУТСКОГО ЭТНОСА В КОНТЕКСТЕ РАЗВИТИЯ ГАСТРОНОМИЧЕСКОГО ТУРИЗМА РЕГИОНА

Народ саха проживает на территории Республики Саха (Якутия), расположенной в северовосточной части Сибири. Почти 40 \% территории страны находится за Полярным кругом в зоне вечной мерзлоты. Климат резко континентальный.

Народ саха тюрко-монгольского происхождения пронёс свои уникальные традиции и обычаи сквозь века. Прибыв из своей южной прародины на далёкую северную территорию, он вынужден был приспосабливаться к новым суровым природным и климатическим условиям, обустраивать свой быт - держать скот, одеваться, охотиться, питаться, чтобы выжить и продолжить свой род, наконец, сохранять обычаи, язык и культуру. Чтобы выжить в условиях долгой и суровой зимы, необходима еда, богатая белками, витаминами и микроэлементами. Здоровье человека напрямую связано с питанием, принципы которого обусловлены видом деятельности, климатическими условиями, временем года.

Естественно, приезд гостей в какую-либо страну, регион не обходится без знакомства с национальной кухней, но этот процесс, как правило, имеет формальный характер. Для подробного знакомства с культурой питания существуют гастрономические туры. Гастрономический туризм увлекательное и содержательно наполненное направление туристского бизнеса, во время которого можно почерпнуть много интересной и полезной информации о менталитете, вековых традициях и национальном духе народов через знакомство с культурой приготовления и употребления пищи.

Следует отметить, что любая страна имеет потенциал для развития гастрономического туризма, основывающегося на демонстрации туристам неповторимости национальной кухни, традициях гостеприимства. Сегодня гастрономический туризм, способствующий возрождению и сохранению национальных кулинарных традиций стран и регионов, популярен и активно развивается во всём в мире, в России медленно, но верно идёт вперёд и имеет большие перспективы для развития.

Каждый регион обладает гастрономическими особенностями, уникальными продуктами и блюдами, которые целесообразно позиционировать для привлечения туристов. Такие мероприятия должны организовывать местные органы государственной власти, туристские фирмы, предприятия общественного питания и все, заинтересованные в развитии имиджа своей страны в целом и отдельных регионов в частности. В Якутии большую помощь в проведении гастрономических мероприятий оказывает некоммерческое партнёрство «Ассоциация рестораторов Республики Саха (Якутия)».

Ассоциация создана в целях развития индустрии питания и улучшения качества обслуживания. Главными задачами партнёрства являются: объединение предприятий общественного питания в единую профессиональную организацию, проведение и участие в профессиональных конкурсах, реклама и продвижение предприятий индустрии питания. Проводятся основные мероприятия, которые организует и курирует Ассоциация в области гастрономии: республиканская выставка-ярмарка «Рестодень» (июнь), фестиваль ухи (июль), выставка-ярмарка «Продовольствие» (сентябрь), республиканский фестиваль строганины (декабрь), гастрономический фестиваль «Вкус Якутии» (декабрь), а также конкурсы искусства поваров, официантов, барменов, кондитеров республики (в течение года).

Так, с целью продвижения бренда Республики Саха (Якутия) и, в частности, бренда местной рыбной продукции в городе Якутске с 1999 года проводятся соревнования в рамках фестиваля строганины. Цели проведения мероприятия: повышение престижа якутской национальной кухни, пропаганда национальных традиций гостеприимства и приготовления рыбных блюд с целью привлечения туристов.

Один из самых широкомасштабных фестивалей был проведён в Якутске в 2011 году в рамках Международной конференции по событийному туризму. В качестве почётных гостей его посетили представители профильных федеральных органов исполнительной власти, двенадцати регионов РФ, эксперты из Финляндии, Германии, Кореи, Японии, Великобритании, представители органов местного самоуправления, научной, туристкой общественности, представители смежных отраслей, ведущих научных и образовательных институтов, эксперты в области маркетинга, 


\section{Учёные записки}

Комсомольского-на-Амуре государственного технического университета

пиар-технологий, представители российских и зарубежных средств массовой информации и коммуникаций.

Во время фестиваля проходят выставки-ярмарки охотничьих ножей, рыболовных снастей, фотографий, соревнования по северному многоборью. На нескольких плащадках города продают замроженную рыбу из северного улуса, проводятся дегустации блюд из строганины, представленных ведущими рестораторами города, проходит блицтурнир ледовых скульпторов.

Самым важным событием фестиваля является конкурс «Строганина», состоящий из традиционных этапов: «Домашнее задание», «Визитная карточка», «Чемпион-рыба», «Перетаривание карасей», «Поедание рыбы», «Скорость и качество строгания».

Самый знаменитый гастрономический бренд Якутии - строганина. Она представляет собой стружку из замороженной до деревянного состояния рыбы. Отрезать полноценный кусок от рыбного полена практически невозможно, поэтому строганина снимается очень острым ножом и походит на белые ледяные кудряшки. Для правильного соблюдения ритуала надо смешать соль и перец по вкусу и макать в эту смесь холодные кусочки. Пальцы замерзают, а язык не успевает замёрзнуть - сырое мясо тает во рту. Конкурс на лучшее строгание рыбы - самое долгожданное и любимое мероприятие якутян.

На следующем этапе праздника жюри оценивает выступления участников в номинации «Царь-рыба». Победители определяются в каждой «весовой категории» рыбы.

Таким образом, с каждым годом фестиваль приобретает всё больший размах. Ещё одним мероприятием в области развития гастрономии в республике является проведение гастрономического фестиваля национальной кухни «Вкус Якутии». Цель и задачи фестиваля: развитие индустрии питания Якутии, популяризация национальной кухни, создание туристской привлекательности Якутска, благоприятного имиджа предприятий общественного питания, знакомство жителей и гостей города с особенностями национальной культуры питания, демонстрация профессионального мастерства кулинаров города, обмен профессиональным опытом. Этот проект, стартовавший в рамках масштабного фестиваля «Зима начинается с Якутии», был направлен на формирование и продвижение бренда якутской национальной кухни.

Торжественное открытие мероприятия состоялось в Окружной администрации города Якутска во время круглого стола рестораторов на тему «Развитие локальной гастрономии». Обсуждались основные направления, в которых должна развиваться якутская кухня, чтобы завоевать большую популярность. Как считают организаторы мероприятия, Якутия должна искать новые идеи для развития локальной гастрономии, не ограничиваясь популяризацией только строганины и северной рыбы, которую могут предложить и другие северные регионы.

В рамках мероприятия «Вкус Якутии» проходят соревнования между ресторанами столицы на самое лучшее национальное блюдо. В конкурсе национальных блюд принимают участие рестораны «Усадьба Атласовых», «Чочур Муран», «Лайнер», «Полярная звезда», Mammoth, «Тыгын Дархан», «Кружало» и др. На фестивале было продемонстрировано 171 блюдо. Прошли проектные сессии «Новые продукты для продвижения якутской гастрономии» и «Новая мифология якутской гастрономии и гастротуризма». Завершается фестиваль выставкой-ярмаркой северных деликатесов.

Таким образом, гастрономический фестиваль «Вкус Якутии» в рамках фестиваля «Зима начинается с Якутии» продемонстрировал перспективы развития гастрономической и культурной уникальности республики.

Поводя итоги, отметим, что фестивали «Строганина» и «Вкус Якутии» приобрели популярность у всех жителей республики. Якутия имеет богатейшие гастрономические сокровища, которые могут выйти на международный уровень и способствовать развитию и совершенствованию в регионе гастрономического туризма.

Вместе с тем исследование повседневной культуры питания народов Саха должно, по нашему мнению, опираться не только на рассмотрение традиционных обрядов, организацию праздничного питания, но и исследовать пищевые привычки представителей всех этносов региона, выявлять в них общее и особенное, рассматривать их взаимосвязь с системой культуры в целом. 
Винокурова М. А., Коноплёва Н. А.

ПРОДВИЖЕНИЕ ПОВСЕДНЕВНОЙ КУЛЬТУРЫ ПИТАНИЯ ЯКУТСКОГО ЭТНОСА В КОНТЕКСТЕ РАЗВИТИЯ ГАСТРОНОМИЧЕСКОГО ТУРИЗМА РЕГИОНА

Подобное многоаспектное исследование возможно осуществить на основе междисциплинарного культурологического знания.

С целью узнать линейку существующих и перспективных якутских продуктов и брендов, которые могут стать частью формирования гастрономического облика региона, нами был проведён мини-социологический опрос местного населения на тему «Продуктовый бренд Якутии».

Ответы респондентов совпали с названиями продуктов и брендов, предложенными участниками семинаров гастрономического фестиваля «Вкус Якутии», что позволило структурировать линейку существующих якутских продуктов. Респонденты в своих ответах на первое место по значимости ставят якутские рыбы чир и нельму в варёном, жареном и замороженном видах. На втором месте в линейке продуктов находится карась. Третье место занимает жеребятина. Вместе с тем привычный якутам продукт крайне слабо представлен на российском и мировом рынках. На четвёртом месте коренными жителями Якутии названы дикоросы - амгинская земляника, жиганские ягоды, алданская голубика, таттинская смородина, намская брусника, анабарская морошка. На пятом месте - молочные продукты. Молочные продукты высокого класса могут быть использованы в качестве гастрономических сувениров: сыров, кумыса, сметаны. Озёрный голянь по актуальности оказался на шестом месте. Учитывая, что это яркий местный гастрономический продукт, его следует включать в национальное меню ресторанов, разрабатывать линейку рецептов, брендировать его, сделать частью местных гастрономических сувениров. Замыкают список перспективных якутских продуктов оленина, верхоянские зайцы, бизонье мясо.

Так как кулинарные традиции стран мира являются объектом интереса туристов, становятся одной из целей пребывания, можно аспект повседневной культуры жизнедеятельности использовать для позиционирования и продвижения якутского региона. На сегодняшний день в обществе ярко выражено усиление интереса к гастрономическим брендам. Бренд территории, включающий в себя гастрономический компонент, станет мощным инструментом, который не только поспособствует увеличению популярности туристской дестинации и привлечению туристов, но и возрождению национальных кулинарных традиций и формированию положительного имиджа региона.

В дальнейших исследованиях мы ставим целью проведение историко-культурологического анализа и выявление принципов обыденности в организации культуры питания якутских этносов, играющих важную роль в функционировании культуры сообщества, его жизнедеятельности, формировании региональной идентичности и ценностных смыслов картины мира жителей региона.

\section{ЛИТЕРАТУРА}

1. Бродель, Ф. Структуры повседневности: возможное и невозможное. В 3 т. Т. 1-3. Материальная цивилизация, экономика и капитализм. XV-XVIII вв. / Ф. Бродель. - М., 1986.

2. Дорофеева, 3. Е. Социология культуры и повседневность: лекции [Электронный ресурс]. - Режим доступа: file///Users/Mama/Documents/Повседневность.Лекции Sociologist,s\%20Warenhouse, weberchive.

3. Драчева, Е. Л. Гастрономический туризм: современные тенденции и перспективы / Е. Л. Драчева,

Т. Т. Христов // Российские регионы: взгляд в будущее. - 2015. - № 3(4). - С. 36-50.

4. Ионин, Л. Г. Понимающая социология. Историко-критический анализ / Л. Г. Ионин. - М., $1979 .-427$ с.

5. Кущева, Н. Б. Гастрономический туризм как перспективный вид туризма регионов России / Н. Б. Кущева,

Т. В. Бедяева // Современные исследования социальных проблем. - 2014. - № 12(44). - С. $207-217$.

6. Мотрошилова, Н. В. Принципы и противоречия феноменологической философии / Н. В. Мотрошилова. М.: Высшая школа, 1968. - 127 с.

7. Поляков, Ю. А. Человек в повседневности (исторические аспекты) / Ю. А. Поляков // Труды Института российской истории РАН, 1999-2000. - М.: ИРИ РАН, 2002. - Вып. 3. - С. 290-322.

8. Родионов, Т. П. Национальная кухня: дорогу добрым традициям / Т. П. Родионов. - Илин, 1997. - № 1-2. 2 c.

9. Саввин, А. А. Пища якутов до развития земледелия (опыт историко-этнографической монографии) А. А. Саввин. - Якутск: ИГИ АН РС(Я), 2005. - 376 с.

10. Скульмовская, Л. Г. Повседневность как культурно-историческая категория / Л. Г. Скульмовская, Н. В. Назарова // Теория и практика общественного развития. - 2014. - № 12. - С. 97-100.

11. Фрейд, 3. Психопатология обыденной жизни / З. Фрейд. - СПб.: Эксмо, 1997. - 192 с. 